\title{
Development of Gravitational Acceleration Measurement set up based on Laser Beams
}

\author{
Sadhan Chandra Das, ${ }^{1, a)}$ Sagnik Das, ${ }^{2}$ Nandkishor Ghodke, ${ }^{1}$ Sumant Katiyal ${ }^{3}$, Abhijit Majumdar ${ }^{2}$ \\ ${ }^{1}$ UGC-DAE Consortium for Scientific Research, University Campus, Khandwa Road, Indore-452 001, Madhya Pradesh, India \\ ${ }^{2}$ Indian Institute of Engineering Science and Technology, Shibpur, Botanic Garden, Howrah -711 103 \\ West Bengal, India \\ ${ }^{3}$ Devi Ahilya University, Khandwa Road, Indore-452 001, Madhya Pradesh, India \\ scdas@csr.res.in, sagnikdas123@gmail.com,nand@csr.res.in, sumant578@gmail.com, majuabhijit@gmail.com
}

\begin{abstract}
In this paper, using three parallel laser beams system we have calculated the value of gravitational acceleration (g) by deriving a simple equation, where there is no velocity term, is reported. The numerator of the equation is always positive irrespective of distances. The setup consists of commonly available three red laser light-emitting diodes and three sensors using very common fast transistors. A free-fall object intercepts the laser beams to produce three voltage pulses across the collector-emitters of three transistors. These voltage pulses are fed to a storage oscilloscope for measuring the two time-intervals between two subsequent gaps of three laser beams with millisecond resolutions. Time intervals are also measured by two-microsecond timers in microsecond resolution. The object may fall from any height above first laser beam, but the ' $g$ ' calculated remains the same. Measurements were done by letting an object fall from two different heights, six times from each height, and the average value of ' $g$ ' of 9.8036916315 meters per second squared is calculated using the data of two-microsecond timers, which has a $0.03 \%$ deviation from the standard value of 9.80665 meters per second squared. Results obtained using microsecond timers are more accurate than that obtained using oscilloscope millisecond data.
\end{abstract}

Keywords- Gravitational Acceleration, 'g', Timer, Laser, Transistor,

\section{INTRODUCTION}

The determination of Earth's gravitational acceleration has been done many times since the early observations of Galileo. The acceleration of a free-falling object is due to the gravitational field acting on the object towards the center of the Earth. The formula of the law of gravitational attraction derived by Sir Isaac Newton was published in 1687. Depending on the Earth's latitude and elevation, the gravitational acceleration varies from 976 to $983 \mathrm{Gal}$ (Galileo) i.e. 9.76 to 9.83 meters per second squared (M-Sec $\left.{ }^{2}\right)[1,2]$. The standard or nominal gravitational acceleration $\left(\mathrm{g}_{0}\right.$ or $\left.\mathrm{g}_{\mathrm{n}}\right)$ measured in a vacuum and as defined by International Organization for Standardization (ISO80000) or International Electrotechnical Commission (IEC80000) is $9.80665{\mathrm{M}-\mathrm{Sec}^{-2}}^{2}$ [3]. This value was decided in the third General Conference on Weights and Measures (GCWM) in the year 1901. The other names of $g_{0}$ or $g_{n}$ are standard gravity or standard acceleration due to gravity or standard acceleration of free fall [4-7].
J. S. Clark[8] and A. H. Cook[9] used a reversible pendulum and free-fall experiments to find absolute ' $\mathrm{g}$ ' constant which is very close to the mean of ' $g$ ' absolute values determined by using other methods. The absolute ' $\mathrm{g}$ ' value of $981181.75 \mathrm{mGal}\left(1 \mathrm{mGal}=10^{-5} \quad \mathrm{M}_{-} \mathrm{Sec}^{-2}\right)$ was determined by Cook using the British Fundamental Gravity Station in the National Physical Laboratory (N.P.L), and ' $\mathrm{g}$ ' of $9.801018{\mathrm{M}-\mathrm{Sec}^{-2}}^{2}$ using Institute for Basic Standards, National Bureau of Standards near Gaithersburg, Maryland, Washington D.C. 20234 [10,11]. Recently, 'g' of (979 832 $568.9 \pm 5.0) \mu \mathrm{Gal}$ was determined in the KRISS Watt balance system [12]. In recent past, many researchers have done gravitational acceleration computations by using innovative ideas with complicated systems [13-18].

Common methods to measure ' $\mathrm{g}$ ' in educations are simple pendulum, free fall and weight-based experiments. In the case of a simple pendulum, the error occurs during experiments due to approximation in the mathematical model and experimental assumptions. In many free fall experiments, air resistance is neglected. Weight-based experiments have very poor accuracy due to the limited precision of force meters and force sensors [19].

Recently, N Suwanpayak et al. determined ' $\mathrm{g}$ ' by a motion of free-fall, simple pendulum, physical pendulum and Atwood's machine. The reported measured values are 9.64 $\mathrm{M}-\mathrm{Sec}^{-2}, 9.67 \mathrm{~ms}^{-2}, 10.88{\mathrm{M}-\mathrm{Sec}^{-2}}^{2}$ and $10.47 \mathrm{M}_{-} \mathrm{Sec}^{-2}$, respectively where accuracies are poor [20].

In this paper, using three parallel laser beams system we have calculated the value of gravitational acceleration $(\mathrm{g})$ by deriving a simple equation, where there is no velocity term, is reported. The novelty lies in the derived simple equation for ' $g$ ' calculation, where the difference term on the numerator of the equation is always positive irrespective of values of both the distances between first and second, and second and third parallel laser beams. It is universally true for any linearly accelerated object. The object can be dropped from any height above the first laser beam. On the other hand the entry velocity of the object can be anything, but the value of ' $\mathrm{g}$ ' found is the same. It is because the equation does not contain any velocity term. One mild steel (MS) object is used in this experiment. The object is held by an electromagnet and allowed to fall freely. The system including the microsecond timers, is very easy to design, fabricate with a few locally available components, and to operate. It is portable and can be accommodated in a small space. 


\section{DERIVATION OF THE EQUATION AND BASIC EXPERIMENTAL SETUP}

\section{a)}

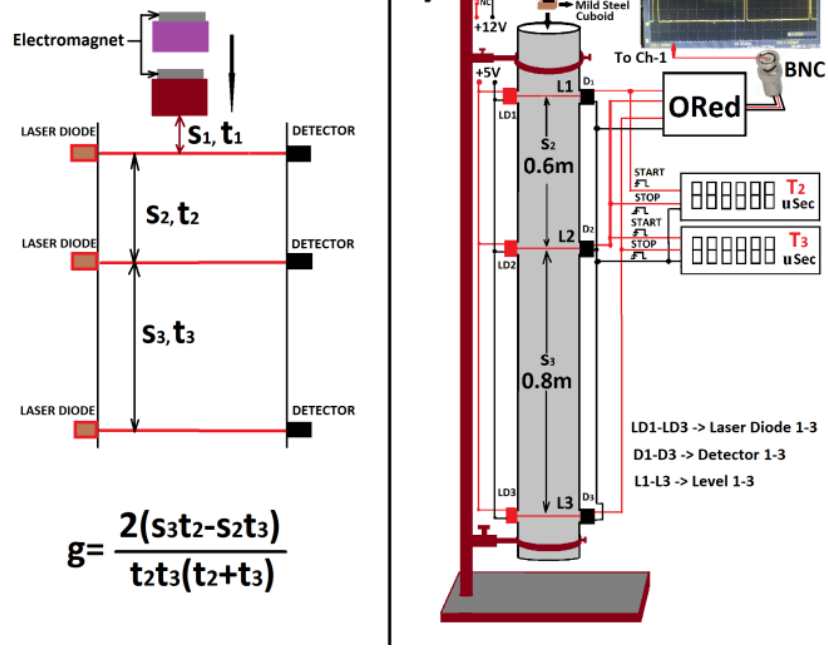

Fig. 1. a) Schematic diagram of the free fall object with three levels detection, b) Blocks of the experimental setup

Recalling the equation of linear motion for a free-falling object due to gravitational acceleration ' $\mathrm{g}$ ', the following equations can be written for the basic diagram of the Fig 1a. Here the initial velocity in each case is zero, as the object is allowed to fall from its resting position.

$$
\begin{aligned}
& \mathrm{S}_{1}=0.5 \mathrm{gt}_{1}{ }^{2} \\
& \mathrm{~S}_{1+} \mathrm{S}_{2}=0.5 \mathrm{~g}\left(\mathrm{t}_{1}+\mathrm{t}_{2}\right)^{2} \\
& \mathrm{~S}_{1}+\mathrm{S}_{2}+\mathrm{S}_{3}=0.5 \mathrm{~g}\left(\mathrm{t}_{1}+\mathrm{t}_{2}+\mathrm{t}_{3}\right)^{2}
\end{aligned}
$$

Here, equations (2)-(1) give

$$
t_{1}=\frac{s_{2}}{g t_{2}}-\frac{t_{2}}{2}
$$

Now, by doing equations (3)-(2) and substituting the term of $t_{1}$, the equation of gravitational acceleration, ' $g$ ' is derived as:

$$
g=\frac{2\left(S_{\mathrm{g}} t_{\mathrm{z}}-S_{\mathrm{z}} t_{\mathrm{g}}\right)}{t_{\mathrm{z}} t_{\mathrm{g}}\left(t_{\mathrm{z}}+t_{\mathrm{g}}\right)}
$$

Equation (4) shows that the gravitational acceleration ' $\mathrm{g}$ ' measured using the basic system of Fig 1, is a function of $S_{2}$, $S_{3}, t_{2}$, and $t_{3}$. If the $S_{2}$ and $S_{3}$ are kept fixed, then ' $g$ ' is a function of $t_{2}$ and $t_{3}$. So, ' $g$ ' is calculated using the equation of (4) by measuring the time intervals of $t_{2}$ and $t_{3}$ only. Here the air resistance is neglected.

The term, $\left(S_{3} t_{2}-S_{2} t_{3}\right)$ is always greater than zero irrespective of the values of $S_{2}$ and $S_{3}$, which is a universally true term for any linearly accelerated body in motion.

Fig 1b shows the different sections of the experimental setup. The main part of the setup is a 2 meter (M) long PVC pipe of an inner diameter of 40 millimeter $(\mathrm{mm})$ and a wall thickness of $5 \mathrm{~mm}$. It has a three-level detection points. The laser LED $(3 \mathrm{~mW})$ and transistor (BC108C) detector of each level are fixed exactly opposite to each other from the outer surface of the pipe. The distance between the first and second beam levels is chosen as $0.6 \mathrm{M}$ and that, between the second and third levels as $0.8 \mathrm{M}$. These distances can be any value within the length of the pipe. The transistor is made a detector by making a small hole of $1 \mathrm{~mm}$ diameter on the top surface of its metal body. Then it acts as a phototransistor. When laser light enters inside the transistor through the hole, electron-holes pairs are generated for conduction and to bring the transistor in a saturation region. So when laser light of sufficient intensity enters the hole the transistor saturates and the voltage across the collector-emitter becomes low around 0.1 Volts $(\mathrm{V})$. When an object cuts the laser beam during its motion downwards due to the gravitational field, the transistor goes to the cutoff region making collectoremitter voltage high around $5 \mathrm{~V}$. The biasing voltage of the transistor is $5 \mathrm{~V}$. The transistor remains at the cutoff region as long as the object passes through the laser beam. A similar effect happens when the object crosses the other two beams. It is the fact that as the object travels downwards by more and more, its velocity increases due to gravitational acceleration. As a result, the progressive pulse widths on the oscilloscope become smaller and smaller. The signals of the three levels are ORed and then inputted to an input channel of the storage oscilloscope (Teledyne Lacroy, Wave Ace $2024,200 \mathrm{MHz}, 2 \mathrm{GS} / \mathrm{s})$. The values of time intervals are read from the oscilloscope. Reading between two rising edges of the first two pulses on oscilloscope gives the value of $t_{2}$ and that, between the rising edges of second and third pulses measures the value of $t_{3}$. In this case, during measurement, the oscilloscope time scale is set as 25 millisecond/division. The distances of $S_{2}$ and $S_{3}$ are known and time intervals of $t_{2}$ and $t_{3}$ are found from the storage oscilloscope. Now, the value of gravitational acceleration ' $\mathrm{g}$ ' is calculated by putting those values in the equation number (4).

The time periods of $t_{2}$ and $t_{3}$ can also be measured by using two-microsecond timers with external edge-triggered start-stop voltage inputs of the timers as shown in Fig $1 \mathrm{~b}$. The trigger input voltage pulses are nothing but the pulses generated by the detectors. Here one object of mild steel is used. The object is held by an electromagnet which is always powered by a supply of $+12 \mathrm{~V}$ through a normally closed (NC) switch. The switch is pushed to cut off the electrical power to de-energize the electromagnet. Hence, the object falls freely. The object can be made of anything. As mild steel can be held by electromagnet for a free-fall, hence it is used in this experiment.

It is seen that the value of ' $\mathrm{g}$ ' calculated from the data of microsecond timers is closer to the standard value of ' $g$ ' than that calculated from the data of the storage oscilloscope. This is due to the resolution of time measurements. The time resolution in the oscilloscope is in milliseconds where as that of the timers is in microseconds. Microsecond timer option is preferred for better accuracy and portability of the setup.

\section{TIME MEASUREMENTS}

Two time intervals $\left(t_{2}\right.$ and $\left.t_{3}\right)$ can be measured in two time resolutions:

\section{A. Oscilloscope time resolution in millisecond range}

B. Microsecond time resolution using microsecond timer

Using the setup, time can be measured by using a storage oscilloscope and/or microsecond timers. The signals of the three levels are ORed and then inputted to an input channel of the storage oscilloscope. The values of time intervals are read from the oscilloscope. The oscilloscope time scale (set as 25 millisecond/division in this case) reading between two 
rising edges of the first two voltage pulses gives the value of $t_{2}$ and that, between the rising edges of second and third voltage pulses measures the value of $t_{3}$. The time values can directly be observed on the oscilloscope screen and the same can be saved in a storage device as well, like USB for further processing by using ORIGIN or EXCEL software.

Time intervals in this setup can also be measured by using two microsecond timers. These timers make it standalone, portable, and measure relatively accurate time intervals as compared to the oscilloscope. Fig 2 shows the blocks of time intervals measurement circuits.

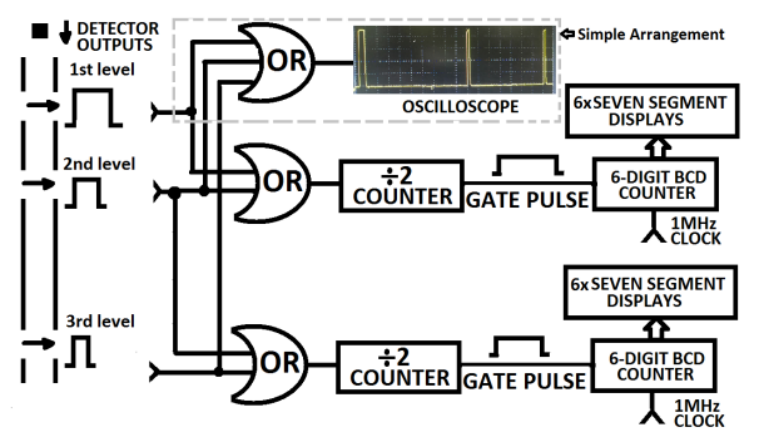

Fig. 2. Blocks of time intervals measurement circuits

Fig 3 shows the detailed gating and control circuits for the microsecond timers section. Reset pulse is generated by a mono-shot IC (Integrated Circuit), to reset all flip-flops and timer circuits before each experiment is started. The gate pulse for counting $1 \mathrm{MHz}$ pulses is generated by $\mathrm{D}$ flip-flops. Oscillator is a crystal controlled circuit for generating $1 \mathrm{MHz}$ clock Transistor-Transistor Logic (TTL) pulses, which are fed to the timer circuits for the time duration of the gate pulse width. The start and stop signals for the generation of the gate pulses come from outputs of the detectors.

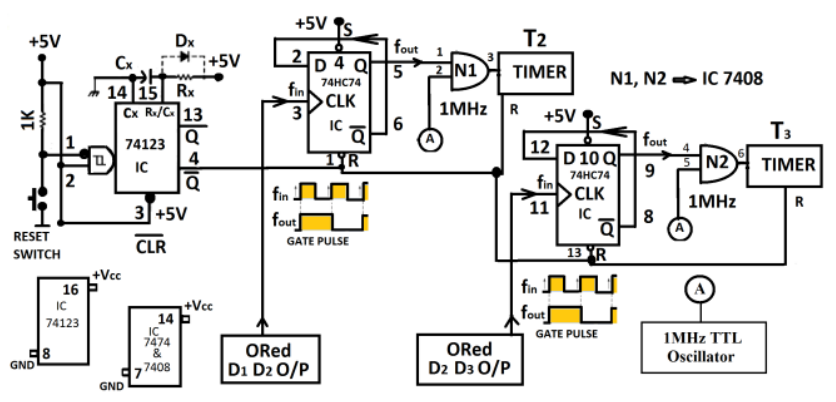

Fig. 3. Gating circuits for the timers

\section{RESULTS AND DISCUSSION}

Experiments have been done at Normal Temperature and Pressure (NTP) in a place, where Latitude, Longitude, and elevations are $22.692633^{\circ}$ Easr, $75.867607^{\circ}$ North, and 565Meters respectively [21].

Here two types of data are presented,

A. Oscilloscope data (millisecond)

B. Microsecond timer data (microsecond)

\section{A. Oscilloscope data}

Fig 1 (a), (b), (c), (d), (e) and (f) show plotted six waveforms of the free falling object from one (first) position.
Before the data collection, the oscilloscope time scale is set as $25.0 \mathrm{~ms} / \mathrm{div}$. (millisecond per division).

Fig 5 (a), (b), (c), (d), (e) and (f) show the corresponding oscilloscope screen displays (Photos) of the waveforms for six free falls of the object from its first position. Both plotted and displayed data match each other.

Table 1 shows data for six free falls of the object from its first position (Oscilloscope display readings). The average value of the first six readings of ' $\mathrm{g}$ ' is $9.783986188 \mathrm{M}-\mathrm{Sec}^{-2}$ ( 9.78).
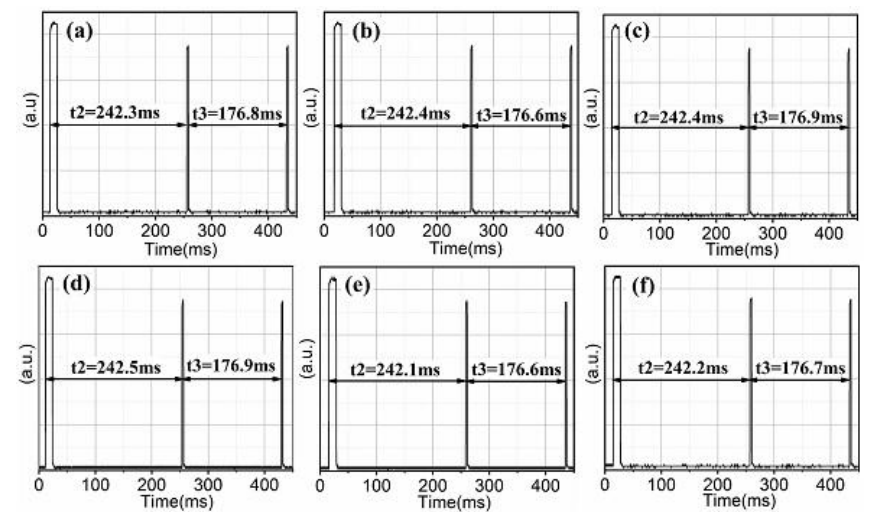

Fig. 4. Plotted six waveforms of the free fall object from one (first) position (Oscilloscope data); here (a), (b), (c), (d), (e) and (f) show ORIGIN plotted six waveforms of the free falling object from one position.

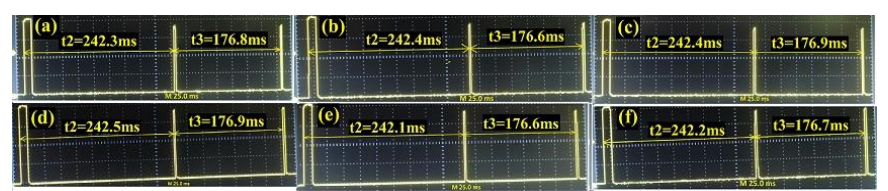

Fig. 5. Oscilloscope screenshots of first six falls of the object; here (a), (b), (c), (d), (e) and (f) show the corresponding oscilloscope screen displays (Photos).

TABLE I. DATA FOR SIX FALLS OF THE OBJECT FROM ITS FIRST POSITION (OSCILLOSCOPE READINGS)

\begin{tabular}{|c|c|c|c|c|c|}
\hline $\begin{array}{l}\text { Sl. } \\
\text { No } \\
\text {. }\end{array}$ & $\begin{array}{c}\mathrm{t}_{2} \\
(\mathrm{mSec})\end{array}$ & $\begin{array}{c}\mathrm{t}_{3} \\
(\mathrm{mSec})\end{array}$ & $\begin{array}{l}\mathrm{N}=2\left(\mathrm{~S}_{3} \mathrm{t}_{2}-\right. \\
\left.\mathrm{S}_{2} \mathrm{t}_{3}\right) \times 10^{-3} \\
\mathrm{M}-\mathrm{Sec}\end{array}$ & $\begin{array}{c}\mathrm{D}=\mathrm{t}_{2} \mathrm{t}_{3}\left(\mathrm{t}_{2}+\mathrm{t}_{3}\right) \mathrm{x} \\
10^{-9} \\
\text { Sec }\end{array}$ & $\begin{array}{c}\mathrm{g}=\mathrm{N} / \mathrm{D} \\
\left(\mathrm{M}-\mathrm{Sec}^{-2}\right)\end{array}$ \\
\hline 1. & 242.3 & 176.8 & 175.52 & 17953674.02 & 9.776271966 \\
\hline 2. & 242.4 & 176.6 & 175.92 & 17936484.96 & 9.807941767 \\
\hline 3. & 242.4 & 176.9 & 175.56 & 17979818.81 & 9.764280823 \\
\hline 4. & 242.5 & 176.9 & 175.72 & 17991526.05 & 9.766820197 \\
\hline 5. & 242.1 & 176.6 & 175.44 & 17901459.88 & 9.800318029 \\
\hline 6. & 242.2 & 176.7 & 175.48 & 17927554.39 & 9.788284346 \\
\hline \multicolumn{5}{|r|}{ Average $=$} & $\begin{array}{c}9.783986188 \\
(\sim 9.78)\end{array}$ \\
\hline
\end{tabular}

Fig 6 (a), (b), (c), (d), (e) and (f) show plotted six waveforms of the free falling object from its another 
(second) position. The second free fall position of the object is below 10 millimeter from its first position.

Fig 7 (a), (b), (c), (d), (e) and (f) show the corresponding the oscilloscope screen displays (Photos) of six falls of the object from its another (second) position.
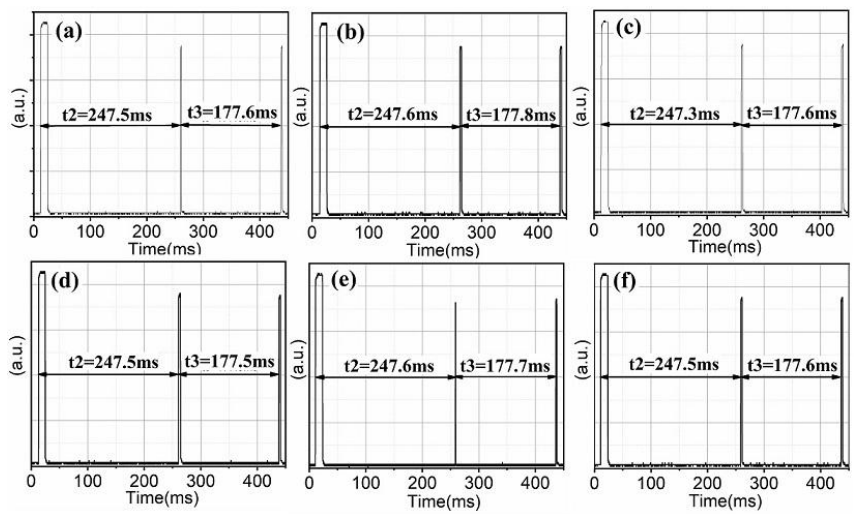

Fig. 6. Plotted six waveforms of the free fall object downing object position by $10 \mathrm{~mm}$ from its previous position (Oscilloscope data); here (a), (b), (c), (d), (e) and (f) show plotted six waveforms of the free falling object from its second position.

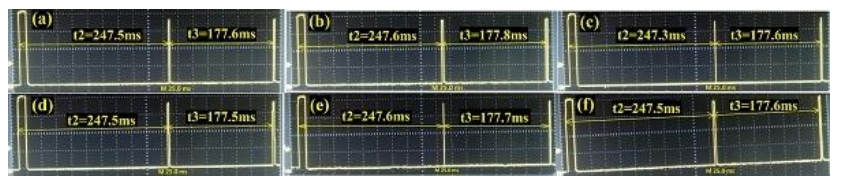

Fig. 7. Oscilloscope displays of second six falls of the object; (a), (b), (c), (d), (e) and (f) show the corresponding oscilloscope screen displays (Photos).

TABLE II. DATA COLLECTED AFTER DOWNING THE OBJECT OF FREE FALL BY 10MM

\begin{tabular}{|c|c|c|c|c|c|}
\hline Sl. & $\mathrm{t} 2$ & $\mathrm{t} 3$ & $\begin{array}{c}\mathrm{N}=2(\mathrm{~S} 3 \mathrm{t} 2- \\
\mathrm{S} 2 \mathrm{t} 3) \times 10^{-3}\end{array}$ & $\begin{array}{c}\mathrm{D}=\mathrm{t} 2 \mathrm{t} 3(\mathrm{t} 2+\mathrm{t} 3) \mathrm{x} \\
10^{-9}\end{array}$ & $\mathrm{~g}=\mathrm{N} / \mathrm{D}$ \\
$\left(\mathrm{M}-\mathrm{Sec}^{-2}\right)$ & $\mathrm{Sec}$ & \\
\hline 1. & 247.5 & 177.6 & 182.88 & 18685695.60 & 9.787165750 \\
\hline 2. & 247.6 & 177.8 & 182.80 & 18727503.31 & 9.761044864 \\
\hline 3. & 247.3 & 177.6 & 182.56 & 18661811.95 & 9.782544186 \\
\hline 4. & 247.5 & 177.5 & 183.00 & 18670781.25 & 9.801410961 \\
\hline 5. & 247.6 & 177.7 & 182.92 & 18712570.56 & 9.775247041 \\
\hline 6. & 247.5 & 177.6 & 182.88 & 18685695.60 & 9.787165750 \\
\hline \multicolumn{7}{|c|}{ Overall average (Table 1 and Table 2)= } & 9.783207974 \\
\hline \multicolumn{7}{|c|}{ Deviation from standard value of g=9.80665ms } & $\sim 0.24 \%$ \\
\hline
\end{tabular}

\section{B. Microsecond timers data}

Fig 8 shows the photos of displays of readings of microsecond timers where readings of Fig 8 (a) are for one (first) position of the object of free fall, and Fig 8 (b) for second position of the object, which is below $10 \mathrm{~mm}$ from its first position of the free falling object.

Table 3 shows the data of the microsecond timers and the calculated value of ' $g$ ' using the equation No. 4. The calculated average value of ' $\mathrm{g}$ ' from first six readings is $9.806024937 \mathrm{M}-\mathrm{Sec}^{-2}$, and that from second six readings is $9.801358326 \mathrm{M}-\mathrm{Sec}^{-2}$. The overall value of ' $\mathrm{g}$ ' from the microsecond timer readings is $9.8036916315 \mathrm{M}-\mathrm{Sec}^{-2}$, which deviates from the standard value of ' $\mathrm{g}$ ' of $9.80665 \mathrm{M}-\mathrm{Sec}^{-2}$ by approximately $0.03 \%$. Here in the table 3 , the calculations are done after converting microseconds to millisecond to maintain similarity with other tables.

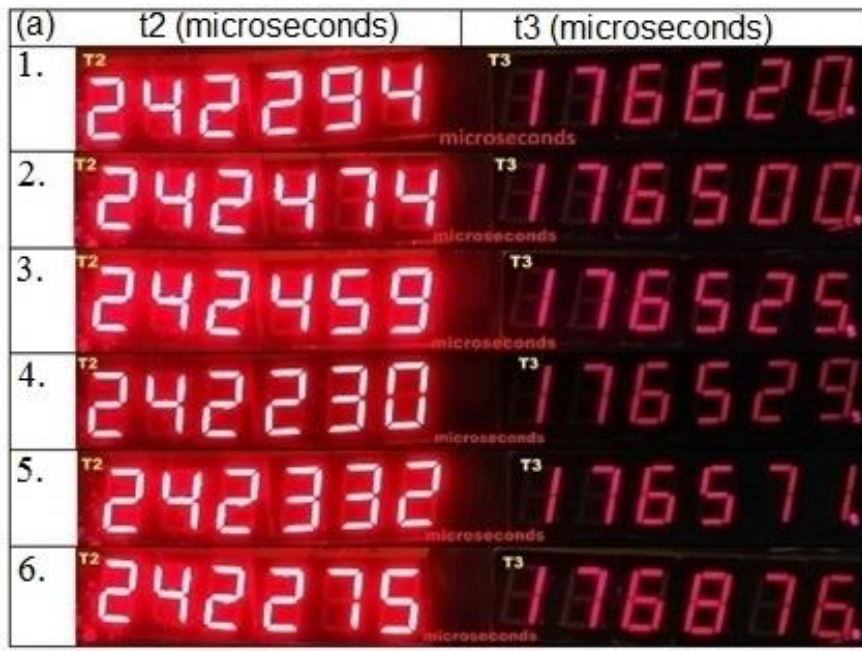

(b) Readings snapped downing the object by $10 \mathrm{~mm}$ from previous its position

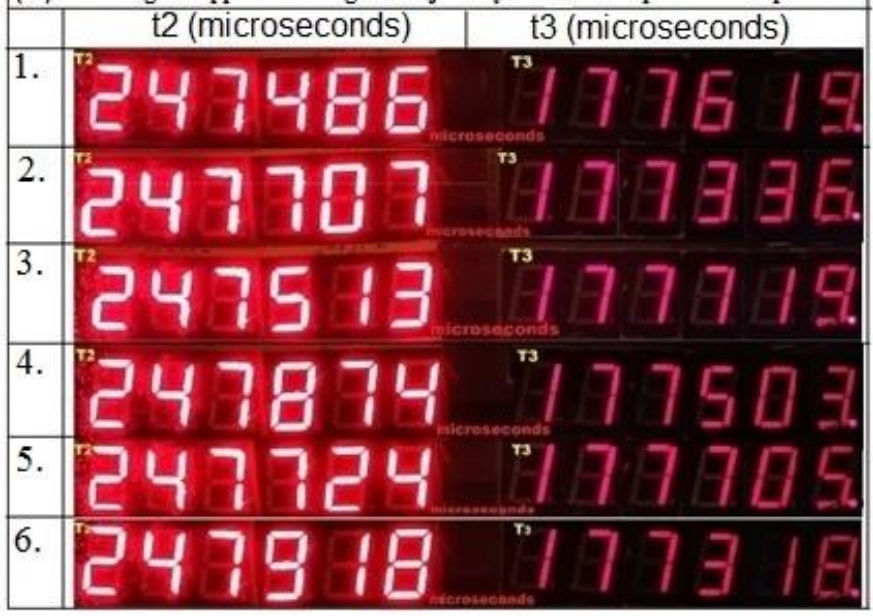

Fig. 8. Photos of displays of readings of microsecond timers (a) for first position, (b) for second position after downing the free fall object by $10 \mathrm{~mm}$

TABLE III. DATA FROM MICROSECOND TIMERS AND CALCULATED VALUE OF ' $G$ '

(a) Data readings using microsecond timers for first position of the object

\begin{tabular}{|l|c|c|c|c|c|}
\hline $\begin{array}{l}\text { Sl. } \\
\text { No }\end{array}$ & $\begin{array}{c}\mathrm{t}_{2} \\
(\mathrm{mSec})\end{array}$ & $\begin{array}{c}\mathrm{t}_{3} \\
(\mathrm{mSec})\end{array}$ & $\begin{array}{c}\mathrm{N}=2\left(\mathrm{~S}_{3} \mathrm{t}_{2^{-}}\right. \\
\left.\mathrm{S}_{2} \mathrm{t}_{3}\right) \times 10^{-3}\end{array}$ & $\begin{array}{c}\mathrm{D}=\mathrm{t}_{2} \mathrm{t}_{3}\left(\mathrm{t}_{2}+\mathrm{t}_{3}\right) \mathrm{x} \\
10^{-9}\end{array}$ & $\mathrm{~g}=\mathrm{N} / \mathrm{D}$ \\
& & & $\mathrm{M}-\mathrm{Sec}$ & $\mathrm{Sec}$ & $\left({\left.\mathrm{M}-\mathrm{Sec}^{-2}\right)}\right.$ \\
\hline 1. & 242.294 & 176.620 & 175.7264 & 17926991.59 & 9.802336277 \\
\hline 2. & 242.474 & 176.500 & 176.1584 & 17930688.25 & 9.824408162 \\
\hline
\end{tabular}




\begin{tabular}{|c|c|c|c|c|c|}
\hline 3. & 242.459 & 176.525 & 176.1044 & 17932546.61 & 9.820378769 \\
\hline 4. & 242.230 & 176.529 & 175.7332 & 17906394.33 & 9.813991402 \\
\hline 5. & 242.332 & 176.571 & 175.8460 & 17924358.18 & 9.810448901 \\
\hline 6. & 242.275 & 176.876 & 175.3888 & 17961723.93 & 9.764586110 \\
\hline \multicolumn{5}{|r|}{ Average $=$} & 9.806024937 \\
\hline \multicolumn{6}{|c|}{$\begin{array}{l}\text { (b) Data readings after downing the object by } 10 \mathrm{~mm} \text { from its previous } \\
\text { position }\end{array}$} \\
\hline $\begin{array}{l}\text { Sl. } \\
\text { No } \\
\text {. }\end{array}$ & $\begin{array}{c}\mathrm{t}_{2} \\
(\mathrm{mSec})\end{array}$ & $\begin{array}{c}\mathrm{t}_{2} \\
(\mathrm{mSec})\end{array}$ & $\begin{array}{l}\mathrm{N}=2\left(\mathrm{~s}_{3} \mathrm{t}_{2-}\right. \\
\left.\mathrm{s}_{2} \mathrm{t}_{3}\right) \times 10^{-3} \\
\mathrm{M}-\mathrm{Sec}\end{array}$ & $\begin{array}{c}\mathrm{D}=\mathrm{t}_{2} \mathrm{t}_{3}\left(\mathrm{t}_{2}+\mathrm{t}_{3}\right) \\
\mathrm{X} 10^{-9} \\
\mathrm{Sec}\end{array}$ & $\begin{array}{l}\mathrm{g}=\mathrm{N} / \mathrm{D} \\
\left(\mathrm{M}-\mathrm{Sec}^{-2}\right)\end{array}$ \\
\hline 1. & 247.486 & 177.619 & 182.8348 & 18686857.34 & 9.784138482 \\
\hline 2. & 247.707 & 177.336 & 183.5280 & 18671020.51 & 9.829564479 \\
\hline 3. & 247.513 & 177.719 & 182.7580 & 18705004.37 & 9.770540353 \\
\hline 4. & 247.874 & 177.503 & 183.5948 & 18715898.30 & 9.809563883 \\
\hline 5. & 247.724 & 177.705 & 183.1124 & 18728147.55 & 9.777389863 \\
\hline 6. & 247.918 & 177.318 & 183.8872 & 18693512.30 & 9.836952898 \\
\hline & & & & Average $=$ & 9.801358326 \\
\hline & & & Overall & verage value $=$ & $\begin{array}{c}9.8036916315 \\
(\sim 9.80369)\end{array}$ \\
\hline & & & & Accuracy= & $0.03 \%$ \\
\hline
\end{tabular}

Measurement using microsecond data is closer to the standard value of ' $g$ ' than using the oscilloscope data. The calculated value is less than the standard value which may be due to air resistance and elevation of measurement station from the sea level.

\section{CONCLUSION}

Using three parallel laser beams system the value of gravitational acceleration $(\mathrm{g})$ is calculated by deriving a simple novel equation, where there is no velocity term involved. The numerator of the equation is always positive for any linearly accelerated object. The setup is very portable and occupies very less space for high school to research level experiments. The results obtained from microsecond timers data is more accurate $\left(9.8036916315 \mathrm{M}-\mathrm{Sec}^{-2}\right)$ as compared to that $\left(9.783207974 \mathrm{M}-\mathrm{Sec}^{-2}\right)$ from the oscilloscope millisecond data. The setup is a combo unit. The value of ' $\mathrm{g}$ ' can be calculated only by microsecond timers.

\section{ACKNOWLEDGEMENT}

SCD and NLG acknowledge D. M. Phase, Centre Director, A. K. Sinha, Ex-Director of UGC-DAE CSR, Indore, M.P., India for their encouragements, Suresh Bhardwaj, A. Wadikar, and Biswajit Dutta for their help.

\section{REFERENCES}

[1] MacDougal D W 2012 Newton's Gravity: An Introductory Guide to the Mechanics of the Universe (New York: Springer-Verlag) chapter 2 pp 17-36.

[2] https://en.wikipedia.org/wiki/Gal_(unit)

[3] https://en.wikipedia.org/wiki/ISO/IEC_80000

[4] https://en.wikipedia.org/wiki/Standard_gravity

[5] Taylor, Barry N.; Thompson, Ambler, eds. (March 2008).

[6] The international system of units (SI), National Institute of Standards and Technology, p.52, NIST special publication 330, 2008 edition.

[7] Bureau international des poids et mesures. 20 06, pp. 142 143, ISBN 92-822-2213-6.

[8] Clark J S 1939 Philos. Trans. Royal Soc. London 238(787) 65-123.

[9] Cook A H 1965 Metrologia 1(3) 84-114.

[10] Cook A H 1967 Philos. Trans. Royal Soc. London 261(1120) 211-52.

[11] Tate D R 1968 J. Res. Natl. Inst. Stand. Technol. 72(1) 1-20.

[12] Choi I M, Lee K C, Lee S, Kim D and Lee H Y 2017 IEEE Trans. Instrum. Meas. 66(6) 1317-22.

[13] Cesare S, Aguirre M, Allasio A, Leone B, Massotti L, Muzi D and Silvestrin P 2010 Acta Astronaut. 67 702-12.

[14] Lee H, Lee J, Cho J and Chang N 2016 IEEE Sens. J. 16(10) 374655.

[15] Wick K and Ruddick K 1999 Am. J. Phys. 67(11) 962-5.

[16] Jonjana S, Lohawijarn W and Dürrast H 2012 J. Sci. Technol. 34(2) 231-9.

[17] Sirisathitkul C, Glawtanong P, Eadkong T and Sirisathitkul Y 2013 Rev. Bras. Ensino Fís. 35(1) 1-6.

[18] The Physics Teacher 57(6), 403-405 (2019).

[19] Qiaochu Wang et al., Eur. J. Phys. 39 (2018) 015701.

[20] IOP Conf. Series: Journal of Physics: Conf. Series 1144 (2018) 012001.

[21] https://www.distancesto.com/coordinates/in/bhawarkuan-squarelatitude- longitude/history/1318821.html 